\title{
The character of nursing students' critical reflection at the end of their education
}

\author{
Kicki Klaeson ${ }^{* 1,2}$, Mia Berglund ${ }^{1}$, Susanne Gustavsson ${ }^{1}$ \\ ${ }^{1}$ School of Health and Education, University of Skövde, Skövde, Sweden \\ ${ }^{2}$ Skaraborgs Hospital, Department of Oncology, Skövde, Sweden
}

Received: October 25, 2016

Accepted: December 14, 2016 Online Published: December 21, 2016

DOI: $10.5430 /$ jnep.v7n5p55

URL: http://dx.doi.org/10.5430/jnep.v7n5p55

\begin{abstract}
Background: In nursing education, theoretical and practical knowledge are intertwined and integrated in the prospective nurses' lifeworld. To enable this, and to develop a critical reflective approach, students should adopt a critical attitude. This study aims to gain a deeper understanding of the character of prospective nurses' critical reflection.

Methods: This is a descriptive qualitative study. Data were gathered using written narratives, individual and focus group interviews. Qualitative content analysis was employed.

Results: Three themes were identified: being open to changes, distancing oneself, and challenging one's understanding. In the first theme, students' critical reflection was expressed through an openness to changes of self-perception and openness to professional development during the education. In the second theme, critical reflection was identified as variations on distancetaking. Inserting distance from a direct experience makes the experience easier to process, understand and relate to the learner's concept of nursing. In the third theme, courage to question what was taken for granted is identified as a necessity to challenging self-understanding and willingness to engage in uncertainty.

Conclusions: It would appear that the academic part of training, with the possibility of reflection in small groups, provides students with conceptual tools for reflective learning as well as giving them the opportunity to relate critically to professional practice and to the professional nurse role.
\end{abstract}

Key Words: Nursing, Education, Critical reflection, Qualitative, Learning

\section{INTRODUCTION}

Health care places great demands on a nurse's professional skills. Academic training to become a nurse in Sweden leads to a vocational qualification along with a bachelor's degree. This requires experience-based and theoretical knowledge, which are examined and intertwined such that the profession is then practiced with a scientific foundation. Nursing students, therefore, need to develop a critically reflective approach. ${ }^{[1]}$

Socialisation to become a nurse is a complex process, relying on how knowledge and skills are communicated and inte- grated into the profession during education. ${ }^{[2]}$ Additionally, there are major discourses, for example the medical or gender discourse, which dominate the media's view of the nursing profession. ${ }^{[3]}$ Nursing may be considered a preserved occupation because, at its core, older values and stereotypes largely remain in place. ${ }^{[4]}$ Research shows that students tend to have an idealistic view of the profession. It is not until the last year that elements of realism are first noticed by learners, when students see themselves in the role of prospective nurse. ${ }^{[5]}$ In Andrew's study, 14 "Millennial" students (born after 1980) were interviewed about expectations for their future profession two months prior to graduation. Three

* Correspondence: Kicki Klaeson; Email: kicki.klaeson@his.se; Address: School of Health and Education, University of Skövde, Skövde, Sweden. 
overarching themes emerged: the probability of a stressful transition, the expectation of a support safety net, and the expectation of appreciation and respect as a qualified nurse. ${ }^{[6]}$ This is in line with other research describing characteristics of Millennial generation learners. ${ }^{[7,8]}$

Education provides students with knowledge and skills development needed to offer quality care. Higher education typically focuses on student understanding, which involves a qualitative change in a student's view of the profession. ${ }^{[8,9]}$ Recent studies highlight learning, in a caring context, taking place during encounters between caring science, patient lifeworld and student lifeworld. ${ }^{[1]}$ In this encounter, scientific knowledge, which is characterised as abstract, is to be transformed and adjusted to the student lifeworld. Additionally, the problem and challenge of integrating theory and practice in nurse education is also highlighted. ${ }^{[10-12]}$ In research, reflection has been emphasized as central for linking theory with practice during the learning process. ${ }^{[13-15]}$ Students, through meaningful reflections, work with a variety of value sets and approaches. This, in turn, makes discovery and consideration of new versions of experiences and attitudes possible. ${ }^{[16]}$ From a lifeworld perspective, learning needs to be understood as it relates to individual experiences. In the case of higher education, learning needs also to be understood in relation to encounters between student lifeworld and the scientific knowledge of caring. ${ }^{[1,10]}$ Pedagogical strategies create meaningful conditions necessary for a reflective process strengthening the integration between student lifeworld, practice experiences and theoretical knowledge. In undergraduate nursing education, strategies such as reflection involving a process of understanding theoretical knowledge in relation to clinical practice are needed. Furthermore, there is limited research focusing on pedagogical strategies supporting learning in this area. ${ }^{[17,18]}$

A definition of reflection can be transferred from Griffiths and Tann ${ }^{[19]}$ teacher reflection research. They argue that the character of reflection can be described in two ways: a spontaneous here-and-now-reflection and a more systematic and perspective widening reflection. The spontaneous and, in some cases, action-oriented reflection means to act without well-founded motive and explanations. The systematic and perspective widening reflection requires both experience and theoretical basis, that is, a distance to that which is experienced using concepts and theories. Critical reflection in this study is defined as the systematic, experience-based and theoretical analysis.

\section{Aim}

The aim of this study was to gain a deeper understanding of the character of prospective nurses' critical reflection.

\section{Methods}

\subsection{Study design}

This is a descriptive qualitative study, utilizing individual interviews, focus group interviews and written narratives.

\subsection{Settings}

In the nursing program at a local university, where this study was conducted, students are supervised in groups of 8-10; this is called Reflection Supervision in Nursing (RHiO) in which the supervision is led by a specially trained instructor. The student is a member of the same group during years two and three of the program. The aim of RHiO is to deepen students' critical reflection and self-awareness by reflecting on self-experienced encounters from practice and using theoretical knowledge to deepen their understanding.

\subsection{Participants}

Students in their last semester of the nursing program were invited to an interview. To facilitate participation, the interviews took place in connection with compulsory education in the program. The interviews were performed during 2013 and 2014. As a result, 15 informants were recruited with a mean age of 27 (22-46). Both genders were represented with a predominance of the female gender (10/15). All of the students in one course $(\mathrm{N}=31)$ participated in the written narratives 2013. The students were aged between 21 and 49 years $(M=27)$.

\subsection{Data collection}

Two researchers (KK and SG) conducted the data collection of the study's oral component. The informants were able to participate in either a focus group or individual interview. The focus groups and interviews were conducted in a group activity room at the university with the exclusion of one individual interview which was conducted in a similar room in a hospital in connection with the clinical practice. The researchers used an interview guide with three different areas addressing the purpose of the study. The areas were 1) what is a nurse and what kind of nurse will you strive to be? 2) what issues challenge the profession? and 3) what characterizes education for nurses?

Two focus group interviews were carried out to obtain data within the social context of the informants. During the sessions, informants were encouraged to talk to one another, to ask questions, exchange stories and comment on each other's experiences. The researcher steered the focus of the group discussions and ensured that a dialogue occurred among the group members. ${ }^{[20]}$ Individual interviews were also carried out to achieve expressions of the character of prospective nurses' critical reflection. ${ }^{[21]}$ Three such interviews were conducted. The purpose and the topic for the session were 
explained prior to starting the interviews; in addition, there were opportunities for informants to ask questions. The voluntary nature of participation was also emphasised. All interviewers strove to be open and accommodating as possible to each informant's experiences and observations. All interviews and recorded material was conducted in Swedish. Interview duration ranged from 46 to 90 minutes, which reflected the complexity of informant thought.

At the end of the third year, students were requested to submit a written narrative describing how they have learned to be a nurse and what was important for their learning process. Students $(n=31)$ were also asked about their views on the nursing profession and how their thoughts about their future professional role had changed over time. The collected data set consisted of approximately 91 pages of written text. The length of the narratives varied from three to four pages.

\subsection{Data analysis}

The analysis was performed using a qualitative content analysis framework. The recorded audio tapes were transcribed verbatim. Qualitative content analysis incorporates Graneheim and Lundman's framework (2004), which strives for interpretation of the underlying meaning of the text. In contrast to manifest content analysis, which is a systematic description, latent analysis includes interpretations. ${ }^{[22,23]}$

During the analysis, all the researchers participated. After re-reading the material to become familiar with it, meaning units from the text were then handpicked by the research group. This was followed by meaning units being abbreviated to shorter and stronger descriptions of the text substance. In the final stage, researchers subsequently evaluated the texts looking for similarities and differences, which resulted in characteristic subthemes. The subthemes were then analysed to ascertain the character of the participants' reflection. Six different subthemes were ultimately identified and then abstracted into the final three themes.

\subsection{Methodological considerations}

By using different approaches such as interviews and written stories, trustworthiness was achieved. Triangulation facilitated the mixing of two different interview techniques (focus group and individual interviews) and the use of written narratives in the qualitative content analysing process. In this way, the findings of this study developed in an open and inquisitive way. This is in line with guidelines of good qualitative research. ${ }^{[21]}$ It is always difficult to carry out investigations in the student environment as there is a risk that students feel compelled to participate. As researchers, however, we tried to be as open as possible stating that participation was voluntary and that an unwillingness to participate

Published by Sciedu Press would have no consequences on their education. Two of the three researchers were not involved in the nursing education which can also be seen as strength. In addition, one of the researchers belongs to the field of educational sciences.

\subsection{Ethical considerations}

The current study was approved by the Head of the Department. All students in the nursing programs were treated according to the ethical guidelines to which all scientists adhere. ${ }^{[24,25]}$

\section{Results}

The themes identified can be described as aspects of the prospective nurses' capacity for critical reflection. These themes are referred to as: being open to changes, distancing oneself, and challenging one's understanding.

\subsection{Being open to changes}

Students' critical reflection is expressed through openness to changes in their self-perception and being open to their professional development during the education. This openness is considered necessary if students are to become aware of their own progress.

\subsubsection{Open to personal development}

Personal development is about change at different levels related to the development of a professional identity. Students describe how they set personal goals and evaluate this "see your own growth". The personal development is expressed as "develop as a person" which assumes that students are open, curious and have a desire to learn more about oneself. For example, the RHiO occasions developed how they worked with feelings and shared each other's thoughts, feelings and failures, thereby seeing their own personal development. Vocational identity was described as an approach that both promotes and challenges their personal development. Personal skills become a tool of the profession. Personal development is, thus, directly connected with the professional role. This is something that can be interpreted as two parallel processes, where the professional and personal qualities are two close areas.

Assignments and group projects have given the chance to reflect about myself, my thoughts and feelings, my strengths and weaknesses. Come up with different solutions to a problem.

The use of personal skills will become part of the profession that requires courage and personal maturity.

\subsubsection{Open to professional development}

Professional development was made aware by comparison with other professions and by ensuring their own alteration 
over time. Contrasting contributed to the knowledge of the professional role and of student development. The students considered nursing as important. Here is an awareness of the professional competence, but also a satisfaction in comparison; to know what you stand for as a professional. One way to define the profession is to take a clear patient perspective. To do something good for another person is a watchword, but it also means that it is difficult to evaluate the quality of the caregiving which has taken place. This demonstrates an awareness of the difficulties to fully understand another person and to design the care to meet the patient's unique needs. There is subsequently also some criticism of the nurse's way of acting and conducting the profession in a way that can be questioned, for example, when the individual perspective is missing. Students emphasize the difference between taking the perspective of the individual and not doing it.

Yes, but it is clear that one cannot always be professional and it depends on how much energy you put into doing a good job, of course. It is clear that there are some nurses who are a little tired of their job or whatever. That are not quite so motivated and it is clear that there is this bias.

Another way to be open to change is how to value different types of tasks. Graduates who previously focused on technical tasks have changed during the education and widened their perspective to ensure the overall situation for the patient, for example, in connection with ethical stance. At the same time, they are aware that the medical priority is high in emergency medical care because patients are so severely ill and that nurses have the responsibility of many patients. Students reflect on the fact that they have to stand up for and use caring theories in these situations and not fall back to the prevailing practices.

We [nurses] ought to be supportive helping the patient through the illness transition, and that is not the case [in the clinic] that's my experience.

The significance of caring and nursing changes during education. Students will come across different pictures of nurses. The image that gives the greatest impression is the message in nursing education about the patient being in the centre. This is an idea that can create resistance in the practical part of the clinical practice. Students also talk about the general impression as a kind of image that summarizes and creates conclusions. Students indicated that if you can feel safe with the technical tasks, you can then be more involved and engaged when connecting with the patient. Here, the training in CTC will have great importance. The students do not always feel that the focus in their becoming professional is caring with the patient in focus. This is described as a collision where the student sometimes finds it difficult to live up to the expectations from the medical paradigm. Finding someone who stands up for the patient perspective creates a belief that it is possible.

\subsection{Distancing oneself}

Critical reflection is about different forms of distance-taking, namely, taking distance from direct experience to better be able to process, understand and relate to the concept of nursing, also distance-taking supported through education and tools offered in education and by shifting perspective. With the use of nursing concepts and theory, personal texts such as diary writing or patient stories and in dialogue with other students and teachers, the reflection and distance-taking are made possible.

\subsubsection{Distance by writing diary and patient stories}

To document the experience of nursing in different forms of story writing helps the students to be critically reflective about their observations and feelings. The story is described as a way to create a deeper understanding of the situation. "It goes deeper into the individual, the disease and the patient's feelings and my emotions, thoughts and nursing measures". The stories also contribute to the knowledge of oneself. "Learned about myself and how I react in different situations". The nature of those data has an effect of the student's self-reflection, self-knowledge and self-development; they are not just a document to show knowledge. The writing described by a student result in "Coming up with different solutions to a problem". The students also understand that you rarely do not get one right answer. "And you feel really, it is very difficult to cope with the situation and you have many proposals and it is a good forum to broaden the horizons".

A support in the situation, and analysis of, for example, a care situation is to use the concepts and theories that are introduced and used during the education. The concept helps to identify "the tacit knowledge". A concept used is lifeworld "to understand the patient's lifeworld", which also exemplifies the theories which are valuable during the education. The student both uses the concepts and describes how the terms mean something in practice.

\subsubsection{Distance through dialogue with students and teach- ers}

RHiO is a social activity where students get to know each other and where they can share experiences. This is exemplified by "breathing", "being undemanding", and "ventilating thoughts", "receiving feedback and guidance". The dialogue both supports and challenges the students' understanding. Their own and others' stories help to reflect and develop new insight into their roll in nursing. RHiO is described as an "oasis", where you are free to talk about what is meaningful at the time but also to reflect on your own shortcomings. The

ISSN 1925-4040 E-ISSN 1925-4059 
student can discuss freely, without having to spend so much time and energy on what is right and wrong. By putting words to a situation, a new picture of the perceived front will come forward.

I've always been open from the start and found it easy to talk but my mindset has changed. I think that I have developed this ability.

By twisting and turning the problem/situation, it can be seen and understood in a new way. A situation can, for example, be described from the students', patients', relatives', nurses' or physicians' perspective. The RHiO occasion contributes to a more structured analysis of a nursing situation and exposes ethical dilemmas. Nursing concepts help students keep a distance from experience, thereby allowing reflection.

By distancing oneself, the nursing student gets a broader understanding of themselves, their role as a nurse and of the patient situation.

\subsection{Challenging one's understanding}

Challenging one's understanding means having the courage to question what is taken for granted, and to dare to be uncertain. Here are two kinds of challenges that require courage, the challenge of exposing to other students and teachers and the challenge of standing up for the ideal image of nursing.

\subsubsection{Challenge of exposing themselves to other students and teachers}

During the RHiO sessions, students generally expose themselves, displaying emotions, difficulties and mistakes. The student is exposed in the story telling and exposed for questions, even "the silent person gets to speak". This is described as possible because of the permissive atmosphere in RHiO. "One can discuss freely, without having to spend so much time and energy on what to say but you say what feels important to you right now". To challenge oneself means being able to talk about things that feel difficult both in actions and feelings. The RHiO allows no direct preparation for what is to happen other than the fact that the student can decide if a situation is to be described. What happens then in the conversation is unpredictable.

I do not see this as any learning in the same way as seminars and lectures are. But you get an eye opener and the opportunity to discuss things you are thinking.

The quote illustrates a students' hesitation about the meaningfulness and knowledge that RHiO offers. The fact that the student's story is in the centre can be perceived as unusual. One student describes being "forced into challenges" during the RHiO sessions. These are one of the forums that offer practice in the ability to question the seemingly professed. "The school teaches one to become critical, which means that in all situations you must stop and feel whether this really is the best". This involves analysing, take a stand and doing what you yourself think is best.

\subsubsection{Challenge of standing up for the ideal image of nurs- ing}

A natural starting point for prospective nurses is based on the patient perspective. Students talk about "seeing the patient" and to ask questions to understand the patient as well as plan and perform care based on this. The message that the patient perspective is the base for care is clear, however, this base is not as clear in practice. This is perceived as a contradiction between the ideal and the actual or potential. The students describe that it takes courage to stand up for the patient and the care they want to stand for, or which they have learned that they must account for. There is a risk of falling into the prevailing practices and losing the professional belief that students will have at the end of their training. A challenge in the coming profession is "to give all patients the time they need". To stand up for the ideal image of nursing is challenged in practice. "I can't give every patient the same time every day, it is my job as a nurse in a way to assess the need in different situations". The clinical practice initially meant that the students' own lifeworld were challenged. Learning to care for patients is something that challenged the students own understanding at a deep and personal level and challenged their self-image in contact with other staff in the department.

\section{Discussion}

The aim of this study was to gain a deeper understanding of the character of prospective nurses' critical reflection. The result shows that students have the ability to reflect about content through openness for new experiences. The themes identified in the students' stories are: being open to changes, distancing oneself and challenging one's understanding. The results of the study are here discussed from two aspects: prospective nurses' learning process and didactic strategies in nurse education.

Nurse education, similar to other academic professional programs, is characterized by common assumptions, traditions and discourses both consolidated and challenged. The learning process for the prospective nurse means to be influenced by and relate to the implicit and explicit content offered in different educational contexts. ${ }^{[2-4]}$ The teaching practice gives the tools for a scientific approach, ${ }^{[1,11]}$ necessary for nurse competence.

Critical reflection is a kind of scientific approach as it challenges experiences and makes it possible for a systematic critical analysis of the educational content in its different 
practice contexts. The results reveal the tension that can characterize a learning process. The students' perception of the nurse profession is challenged. The scientific knowledge and the clinical practice both give possibilities to distance this perception, a changed understanding of experiences and new knowledge development. ${ }^{[26]}$ Paul Ricœur is inspired by phenomenology in his theory about interpretation and changing of understanding. He describes the commuting between experiences and new understanding. In this learning process, a distance to experiences and understanding is a necessary key. Theories and scientific concepts are tools for widening the perspective, especially in higher education with the goal to reach a scientific approach. ${ }^{[27]}$

The study makes visible how reflective group meetings and written stories help students to both verbalise and process theoretical and experienced based knowledge. It is probable that this learning practice can give students the possibility to express both their experiences and beliefs about the professional role, but also to discuss theoretical knowledge and meaning for the nurse profession. ${ }^{[28]}$

The results of our study can be described as students' reflection basis in the normativity which they perceive in professional practice. The university-based training dictates a lifeworld approach to nursing which may differ from the students' direct experience from professional practice. In the same way, it differs from the perceptions of the profession that the students claim to have had earlier in the education. So far, the students have incorporated the tools to verbalise, describe and relate to the profession and to this experience. These tools are used extensively in the RHiO group and for those students who perceive it, these groups are meaningful and even necessary. The RHiO group meetings may be perceived as a free space where one's story can be challenged and developed through a reflection that can partly be characterized as critical. By writing patient stories, the students practice their critical thinking by using conventional care concepts and nursing theories. This interactivity challenges and develops the students' reflective and analytical attitudes. Implicit in our study, it is revealed that students are largely "controlled" by the objectives of the exam for nursing which runs like a thread through the education. But the interactions especially in the focus group interviews can be interpreted as the students understanding and reacting to these and becoming aware that they are entering the nursing profession with strong and weak sides of themselves. This is in line with research in the same context as our with lifeworld approach. $^{[1,16]}$

One goal of the didactic strategies is to stimulate a more conscious and theory-based critical stance. The purpose is the knowledge which students are expected to have reached at the end of the training. The training is to give students the tools to be developed for the profession by learning how to take a distance, to try and in some cases reach new positions which can be termed as an experience-based and action-focused discussion. ${ }^{[26]}$ A permissive educational climate where students' personal and professional developments are given space also requires both special events and specific teacher competence. An experience-based and action-focused discussion can probably be associated with academic knowledge in a way that can strengthen professional development. Hopefully, this may be the hub that makes sense of the otherness that student nurses experience when they recognize the complexity of caring. In this involvedness, they understand themselves as being different and the otherness appears. In this struggle to gain contact with their otherness, they become assured that they can make changes for the patient. ${ }^{[29]}$ This otherness reflects the findings of Ahlberg in the context of experience of view-turns. Nursing students, occupational therapy and physiotherapy students described these as primarily as reorganization of consciousness in contrast to medical students who mainly described view-turns as an addition to something new. ${ }^{[30]}$

\section{CONClusion}

The results of this study indicate that prospective nurses' learning process are individual. During the training to become a nurse, the students' perception of the profession is challenged. The scientific knowledge and the clinical practice both give possibilities to distance this perception, a changed understanding of experiences and new knowledge development. Learning environment and cooperation between universities and different health facilities will become important in the future. Consequently, didactic strategies in nurse education are extremely important, we therefore see this as an incredible development potential for the future. A question that may be asked is what differences can be identified between the experienced and the newly trained nurses concerning the nature of critical reflection. More research is needed in this field before it is possible to see any definite patterns in these different starting points.

\section{ACKNOWLEDGEMENTS}

We wish to acknowledge the nursing students who participated in this study and the University of Skövde, which funded this study. We are also grateful to Rhonwen Bowen of the University in Skövde for help with proofreading.

\section{CONFlicts OF InTEREST Disclosure}

The authors report no conflicts of interest in this work. 


\section{REFERENCES}

[1] Ozolins LL, Elmqvist C, Hörberg U. A nursing student-run health clinic-an innovative project based on reflective lifeworld-led care and education. Reflective Practice. 2014; 15(4): 415-26. https : //doi.org/10.1080/14623943.2014.900024

[2] Mackintosh C. Caring: The socialisation of pre-registration student nurses: A longitudinal qualitative descriptive study. International Journal of Nursing Studies. 2006; 43: 953-62. PMid:16386255 https://doi.org/10.1016/j.ijnurstu.2005.11.006

[3] Dahlborg-Lyckhage E, Pilhammar-Andersson E. Predominant Discourses in Swedish Nursing. Policy, Politics, \& Nursing Practice. 2015; 10(2): 163- 71. https://doi .org/10.1177/1527154409 338493

[4] Dahlborg-Lyckhage E, Pilhammar-Andersson E. The Importance of Awareness of Nursing Students' Denotative Images of Nursing. Journal of Nursing Education. 2008; 47(12): 537-42. https: //doi.org/10.3928/01484834-20081201-01

[5] Day RA, Field PA, Campbell IE, et al. Students' evolving beliefs about nursing: From entry to graduation in a four-year baccalaureate programme. Nurse Education Today. 2005; 25: 636-43. https://doi.org/10.1016/j.nedt.2005.09.003

[6] Andrews DR. Expectations of Millennial Nurse Graduates Transitioning Into Nursing Administration Quarterly. 2013; 37(2): 152-9. PMid:23454995

[7] Ng E, Schweizer L, Lyons S. New generation, great expectations: a field study of the millennial generation. Journal of Business and Psychology. 2010; 25: 281-92. https://doi.org/10.1007/s1 0869-010-9159-4

[8] Olson M. The "Millennials": first year in practice. Nursing Outlook. 2009; 57: 10-7. PMid:19150262 https://doi.org/10.1016/j. outlook. 2008.06.001

[9] Högskoleförordning (1993:100). The Higher Education Ordinance [In swedish] Available from: https ://lagen.nu/1993:100

[10] Ekebergh M. Lifeworld-based reflection and learning: A contribution to the reflective practice in nursing and nursing education. Reflective Practice. 2007; 8(3): 331-43. https ://doi.org/10.1080/1462 3940701424835

[11] Levett-Jones T. Facilitating reflective practice and self-assessment of competence through the use of narratives. Nurse Education in Practice. 2007; 7(2): 112-9. PMid:17689432 https://doi.org/ 10.1016/j.nepr.2006.10.002

[12] Andersson P, Edberg A. Swedish nursing students' experience of aspects for their learning process and their ability to handle the complexity of nursing degree program. Nursing Education Today. 2012; 32(4): 453-7. https : //doi.org/10.1016/j.nedt.2011.05.011

[13] Avis M, Freshwater D. Evidence for practice, epistemology, and critical reflection. Nursing Philosophy. 2006; 7(4): 216-24. PMid:16965303 https ://doi.org/10.1111/j.1466-769X . 20 $06.00267 . \mathrm{x}$

[14] Binding L, Morck A, Moules N. Learning to see the other: A vehicle of reflection. Nursing Education Today. 2010; 30(6): 591-4. PMid:20071058 https ://doi.org/10.1016/j.nedt.2009.12 .014
[15] Welch L, Jeffries MP, Lyon B, et al. Experiential learning - Integrating theory and research in practice. Nurse Education in Practice. 2001; 26(5): 240-3.

[16] Berglund M, Sjögren R, Ekebergh M. Reflect and learn together - when two supervisors interact in the learning support process of nurse education. Journal of Nursing Management. 2012; 29: 152-8. PMid:22380410 https ://doi.org/10.1111/j.1365-2834.20 11.01368. $\mathrm{x}$

[17] Hörberg U, Carlsson G, Holst H, et al. Lifeworld-led learning taking place in encounter between caring science and the lifworld. Clinical Nursing Studies. 2014; 2(3): 107-15. https ://doi .org/10.543 0/cns . v2n3p107

[18] Westin L, Sundler AJ, Berglund M. Students' experiences of learning in relation to didactic strategies during the first year of a nursing programme: a qualitative study. BMC Medical Education. 2015; 15(49). https://doi .org/10.1186/s12909-015-0338-x

[19] Griffiths M, Tann S. Using reflective practice to link personal and public theories. Journal of Education for Teaching. 1992; 18(1): 69-85. https://doi.org/10.1080/0260747920180107

[20] Kitzinger J. Introducing focus groups. British Medical Journal. 1995; 311: 299-302. PMid:7633241 https://doi.org/10.1136/bmj . 311.7000 .299

[21] Kvale S. InterViews An Introduction to Qualitative Research Interviewing. London: Sage; 1996.

[22] Graneheim UH, Lundman B. Qualitative content analysis in nursing research: Concepts, procedures and measures to achieve trustworthiness. Nurse Education Today. 2004; 24(2): 105-12.

[23] Baxter LA. Content analysis. In: Montgomery BM, Duck S, editors. Studying interpersonal interaction. New York: The Guilford communication series. 1991.

[24] World Medical Association. WMA Declaration of Helsinki - Ethical principles for medical research involving human subjects 2008 [cited 2016 October 12]. Available from: http://www . wma.net/en/30p ublications/10policies/b3/

[25] Swedish Code of Statutes. The Act Concerning the Ethical Review of Research Involving Humans (SFS 2003:460) [cited 201510 July] Available from: http://www .epn.se/en/start/startpage/

[26] Ricoeur P. Time and Narrative 2V, editor: Chicago: Chicago University Press; 1985.

[27] Ricoeur P, Thompson JB. Hermeneutics and the human sciences: essays on language, action and interpretation. Cambridge: Cambridge University Press; 1981. https://doi.org/10.1017/CB097813 16534984

[28] Claesson S, Hallström H, Kardemark W, et al. Ricœurs kritiska hermeneutik vid empiriska studier (Ricoeur critical hermeneutics at empirical studies) [In Swedish]. Pedagogisk Forskning i Sverige. 2011; 16(1): 18-35.

[29] Rydlo C. Fighting for otherness. Student nurses' lived experiences of growing in caring: Örebro; 2010.

[30] Ahlberg K. View-Turns University students' Narratives of Qualitative Changes in Ways of Experiencing Meaning of situations during Educational placement: Gothenburg; 2004. 